\title{
Variation of stereoscopic acuity with observation distance and eye movement characteristics*
}

\author{
STURLA KREKLING \\ Psychological Institute, NLHT, University of Trondheim \\ 7000 Trondheim, Norway
}

It has puzzled research workers in perception that stereoscopic acuity decreases with decreasing observation distance, or, equivalently, increasing angle of convergence. Experimental results presented in this paper, as well as evidence published previously, show that the reduction in acuity might be due to rotation of the eyes around their visual axes during convergence which would introduce a disparity for the test lines. Stereoscopic acuity is known to be worse for disparate images. It was proved experimentally that cyclodisparity did lead to a decrease of stereoscopic acuity, supporting this explanation.

\begin{abstract}
"Stereoscopic acuity" and "stereoscopic threshold" refer to the angular magnitude equivalent of the minimal spatial displacement which corresponds to a just noticeable difference in depth (Graham, 1965). Other conditions being constant, the threshold expressed in seconds of arc, or radians, is generally assumed to be invariant with respect to observation distance or angle of convergence. The validity of this assumption has been questioned by relatively recent work. Ames, Ogle, and Gliddon (1932), Brown, Ogle, and Reiher (1963), and Amigo (1963) show that stereoscopic threshold increases as a function of convergence, i.e., stereoscopic acuity decreases with decreasing observation distance.
\end{abstract}

\section{THE OGLE-WEIL}

EYE-MOVEMENT HYPOTHESIS

It has been speculated that changes of retinal location and size of test fields, retinal illumination, or inaccuracies of measurement might cause the change in threshold. According to Brown et al (1963), these factors could hardly explain the effect. These authors, as well as Ogle and Weil (1958), Ogle (1962), and Amigo (1963), assume that the variation in acuity could be related to changes in eye-movement characteristics associated with observation distance. The Ogle-Weil hypothesis consists of two different assumptions: (1) that stereoacuity is related to characteristics of the micro movements (drifts, flicks, and tremor) of the eyes, (2) that these movement characteristics are related to the angle of convergence in a way that causes stereoscopic acuity to decrease with increasing angle of convergence. The

*This research project (C.00.01-67) was supported by the Norwegian Research Council for Science and the Humanities. relationship between stereoscopic threshold and micro movements has been investigated by Shortess and Krauskopf (1961) applying an optical stabilizing technique. It was concluded that the role of eye movements is of considerably less importance than postulated by Ogle and Weil Krauskopf, Cornsweet, and Riggs (1959) and Riggs and Niehl (1960) measured movement characteristics of the eyes when inspecting an object at various observation distances, applying an optical lever registrating technique. No evidence was found that ocular movement characteristics change during fixation for a range of observation distances, varying from 1 to $6 \mathrm{deg}$ of angle of convergence. Thus, none of the assumptions of the Ogle-Weil hypothesis seem to be tenable.

\section{AN ALTERNATIVE HYPOTHESIS}

Determination of the stereoscopic threshold is the experimental equivalent of determining a point on the horopter (Hering, 1879 ; Tschermak, 1931, 1937, 1954; Ogle, 1962). The horopter is conventionally defined as the points in space which are imaged on corresponding retinal points, and the stereoscopic threshold is a statistical expression of the precision with which these points are determined. According to Hering $(1861-1864$, p. $357 ; 1879$, p. 551$)$, a difference in physical distance is easier to discriminate the closer the objects are to the horopter (Weber's law).

Helmholtz (1962, pp. 431-433) also concludes that relief is more clearly seen the closer the object is to the horopter. Tschermak (1900) claims that the visual system is more sensitive to a distal-proximal displacement when this displacement has the horopter as its point of departure. This is shown by the experiment of Tschermak \& Kiribuchi (Tschermak,
1900), where equidistance matchings are made for increasing magnitudes of disparity of the fields to be matched. The results indicate that the variability of the Ss' matchings increases as the level of disparity of the test fields to be matched increased. The relative size of the stereoscopic threshold might thus indicate the relative magnitude of disparity under which the measurements have been performed, other conditions being constant. Applying this line of reasoning, the increasing stereoscopic threshold with decreasing observation distance might be due to the fact that the test fields are imaged with increasing magnitudes of disparity and consequently lead to greater variability in the Ss' matchings. Our problem, then, is to show what factors could possibly cause this assumed increase of disparity with increasing angle of convergence.

\section{THE RESIDUAL-DISPARITY} HYPOTHESIS

It is generally assumed that convergence is a one-dimensional parameter. It is implicitly assumed that no other macro movements of the eyes are involved than bilateral inward movements of the visual axes. This is equivalent to the assumption that the eyes turn around vertical axes during convergence, which is equivalent to the assumption that the law of Listing is valid during convergence. The studies of Hering (1868), Landolt (1876), Carow (1939), Hermans (1943), and Allen (1954), as well as the present author (Krekling, 1969), have shown that the eyes turn around the visual axes as a function of convergence. This "cyclorotary" movement is monotonically related to the angle of convergence, as shown in Fig. 1. Consequently, vertical test fields imaged on corresponding retinal points or meridians when the visual axes are parallel will not necessarily be imaged correspondingly when the eyes are in a converged position. The cyclorotary movements of the eyes will cause the test fields to be imaged on noncorresponding meridians (cyclodisparity).

It has been known since the work of Nagel (1868) that cyclodisparity induces fusional eye movements. The works of Hofmann and Bielschowsky (1900), Ogle and Ellerbrock (1946), and Kertesz and Jones (1970) have clearly shown that the fusional eye movements generally do not eliminate the introduced disparity. A residual disparity is generally found, and this deviation from complete elimination of dis parity (t ermed "Disparationsrest" by Hofmann and Bielschowsky) tends to increase with increasing magnitude of introduced disparity, as shown by Ogle and 


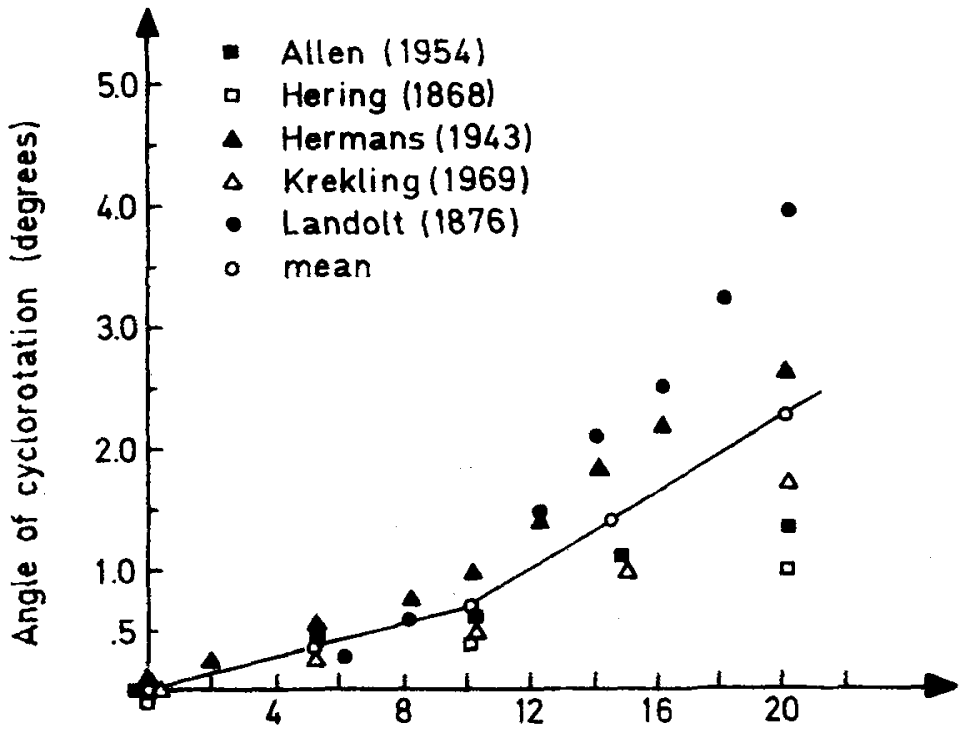

Angle of convergence (degrees)

Fig. 1. Diagram based on five experimental works showing the relationship between cyclorotary movement and angle of convergence, represented on the ordinate and abscissa, respectively. Zero cyclorotary angle means that a pair of corresponding vertical retinal meridians are parallel. A given ordinate value represents a pair of corresponding retinal meridians' angle of intersection. As convergence increases, a vertical test field tends to be more and more disparately imaged on the two retinas as a consequence of the cyclorotary movement.

Ellerbrock (1946). The present author assumes that this is also true when the cyclodisparity is introduced as a consequence of cyclorotary movements associated with an increase in convergence. Consequently, the residual disparity would tend to increase with increasing convergence of the visual axes, and, according to the previous discussion, this might lead to an increase in variability of the Ss' matchings. Nichols (1950), Cibis (1952), Ebenholtz and Walchli (1965), and Adams and Levene (1967) argue that similar stimulus conditions would tend to reduce stereoscopic acuity. The residual-disparity hypothesis might thus be a possible explanation of the variation in stereoscopic threshold reported in the literature. To test this assumption, an experiment was performed simulating the optical conditions assumed to have been present in the experiments reporting changes in stereoacuity with observation distance.

\section{METHOD}

A slightly modified haploscopic design described by Ellerbrock (1954) was used. Five pairs of vertical induction lines (i.1.) were presented to each eye, half of them above and half below the binocularly fused test field (St). These sets of lines were rotated in opposite directions for left and right eye around a horizontal axis passing through the midpoint of the test field and perpendicular to the plane of the induction lines. This rotation of the induction lines would bring the images of the test lines onto noncorresponding retinal meridians. St and i.l. were introduced to left and right eye by reflection in two 50:50 transmission mirrors, through which a vertical comparison test field (Co) was seen. Co was made of a black steel rod and was adjustable in depth by a pulley system, sliding on an optical bench. The comparison stimulus was to be matched with respect to apparent distance to the standard stimulus. St was imaged foveally, the angular separation between $\mathrm{St}$ and Co was $1 \frac{1}{2} \mathrm{deg}$, and they were both $5 \mathrm{x}$ $1 / 16$ deg angular size. St, Co, and i.l. all appeared as black bars or lines against a homogeneous white background, as shown schematically in Fig. 2. The luminance of the background was $140 \mathrm{~mL}$.

The induction lines were rotated in opposite directions for left and right eye and were set at eight different positions. For each position, the stereoscopic threshold was determined by adjusting $C o$ until it appeared equidistant to St, using the method of adjustment. Position of the head was secured by a biteboard, and the time of inspection for each setting was $30 \mathrm{sec}$.
RESULTS

The results are shown in Fig. 3. The stereoscopic threshold expressed in seconds of arc is plotted against rotation of the disparity-inducing lines. Each plotted point represents the standard deviation of 30 observations from one well-trained $S$ with no known visual defects. The

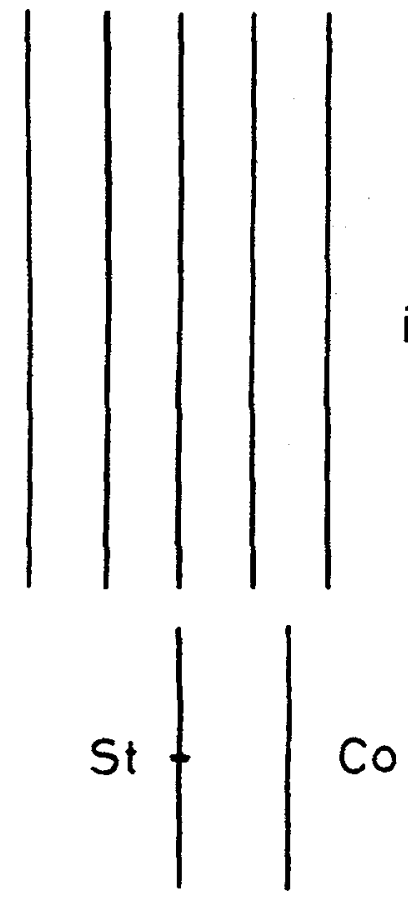

i. 1 .

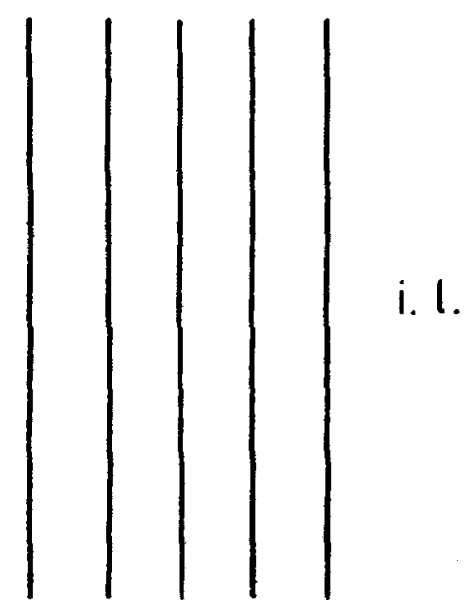

Fig. 2. Figure illustrates how induction lines (i.1.), standard (St), and comparison (Co) appeared in fused binocular vision. The lines appeared suspended in the air somewhere between the $O$ and the homogeneous white background. Angular dimensions: $\mathrm{St}=\mathrm{CO}_{0}=5 \mathrm{deg} \mathrm{x}$ $1 / 16 \mathrm{deg}$, i.l. $=12 \mathrm{deg} \times 1 / 16 \mathrm{deg}$; separation between St and Co is $11 / 2$ deg, geparation between i.l. lines is 1 deg. 
difference between the threshold for zero position and thresholds determined when rotation of induction lines is equal to or greater than 6 min of arc is significant beyond $p=.01$. At $18-20 \mathrm{~min}, \mathrm{St}$ and $\mathrm{Co}$ appeared tilted with respect to each other and matchings became ambiguous.

\section{DISCUSSION}

According to our results, a $100 \%$ increase in threshold is associated with an increase of disparity from 0 to $18 \mathrm{~min}$ of arc. Ogle and Ellerbrock (1946) reported that the deviation from complete elimination of introduced disparity equals $18 \mathrm{~min}$ of arc when a cyclodisparity of $0.8 \mathrm{deg}$ was introduced. During convergence, the rotary component of the eyes induced by convergence is approximately equal to $0.8 \mathrm{deg}$ when convergence is increased from 0 to $15 \mathrm{deg}$, as shown in Fig. 1. Accordingly, one would expect that the stereoscopic threshold in the experiments of Ames et al (1932) and Amigo (1963) would double from 0 to $15 \mathrm{deg}$ of convergence. The results from Ames et al, using the rod horopter technique, lower trace in Fig. 4, indicate that variability of settings more than double for this interval of convergence. In this method, the $S$ adjusts a series of vertical rods until all appear to lie in the apparent frontoparallel plane that

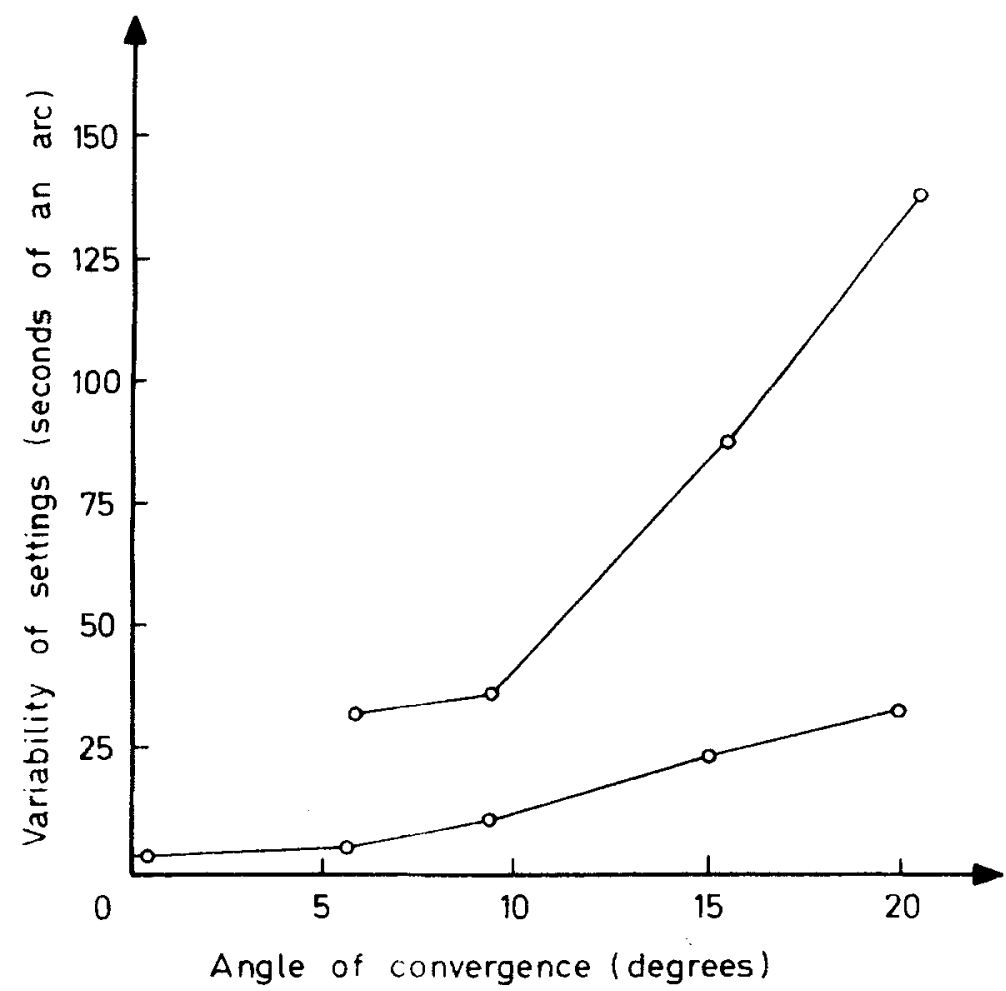

Fig. 4. Relationship between angle of convergence and variability of the Ss' matchings for two different horopter techniques. Upper trace refers to data from the nonius technique, lower trace to data from the rod technique. Based on data reported by Ames et al (1932).

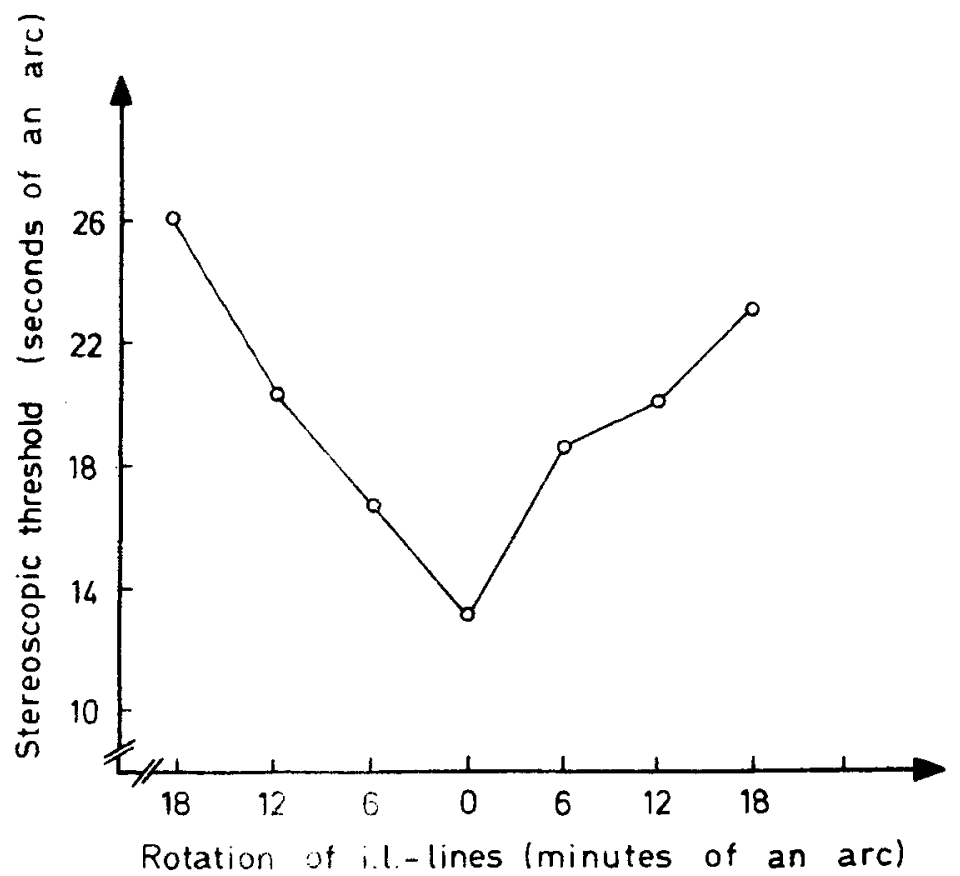

Fig. 3. Stereoscopic threshold measured in seconds of arc plotted against disparity introduced by rotation of i.l. lines, rotation measured in minutes of arc. The diagram shows how variability in settings of Co increases as a function of the disparity. includes the fixation line (Ogle, 1962). The results of Amigo, as shown in Fig. 5, indicate a similar relationship. It was observed by Ogle and Ellerbrock (1946) that the cyclofusional movements are rather slow. Accordingly, after presenting the inducing disparity, a certain time (not specified) will elapse before the eyes have reached their maximum position. The residual disparity would thus tend to be greater for a given angle of convergence, the shorter the exposure time of the fusional inducing test fields. As shown in Fig. 5 , the results from Amigo (1963) indicate an increase in threshold with decreasing exposure time. For a given angle of convergence ( $5 \mathrm{deg}$ ), the difference in threshold is on the average 15 sec of arc for exposure times of 1 and 0.1 sec. According to Ogle and Weil (1956), a reduction in exposure time from 1 to 0.1 sec results in an increase in stereoscopic threshold less than $10 \mathrm{sec}$ of arc. It seems that the increase in threshold found by Amigo is greater than would be expected. This "unexpected" increase might be due to an increase in residual disparity due to the slowness of fusional movements. The slowness of fusional movements would also explain that the difference between short and long 


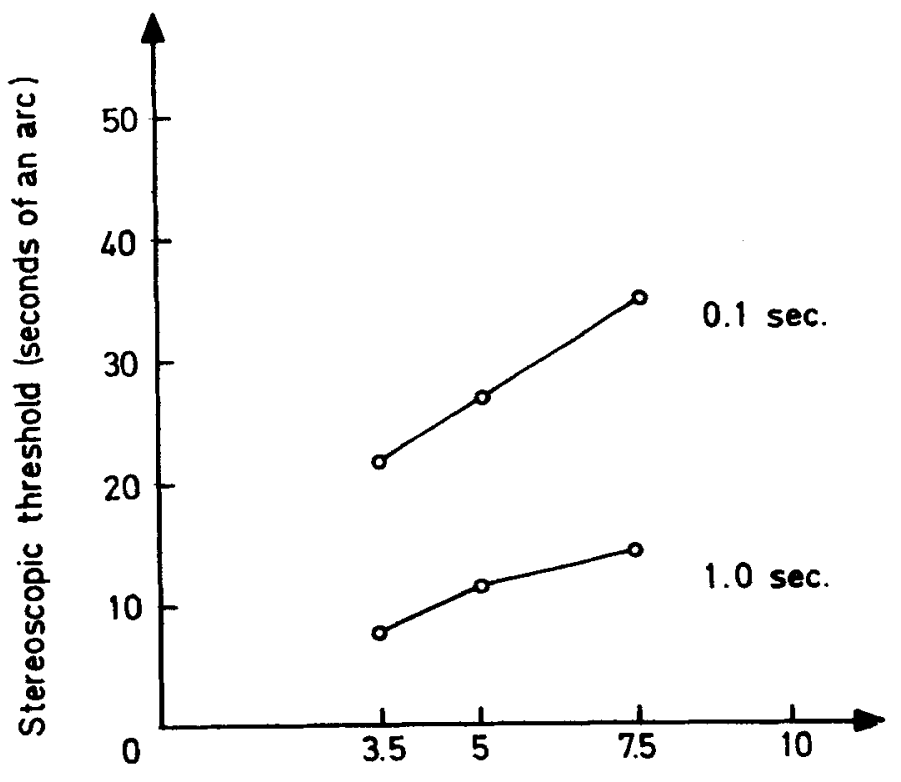

Angle of convergence (degrees)

Fig. 5. Standard deviation of Ss' settings measured in seconds of arc plotted against angle of convergence for exposure times of 0.1 and $1.0 \mathrm{sec}$, based on data from Amigo (1963). The difference in slope is assumed to be related to eye-movement characteristics. An exposure time of $0.1 \mathrm{sec}$ is not sufficient for cyclofusional movements to occur and compensate the disparity introduced by cyclorotary eye position associated with convergence.

exposure times increases with increasing angle of convergence. According to Nagel (1868), Hofman and Bielschowsky (1900), Ellerbrock (1946), Ogle and Ellerbrock (1946), and Ellerbrock (1954), the cyclofusional amplitude depends on the number of binocularly presented contours in the visual field-the fewer the vertical contours, the less the cyclofusional amplitude. Accordingly, cyclofusional movements would not be expected to occur in the nonius method since the half images are monocular. As a consequence of the cyclorotary movement associated with convergence, the two halves of the test fields in the nonius method would be imaged on noncorresponding retinal meridians, thus increasing the variability in alignment of the monocular half rods. For a given angle of convergence, using the nonius horopter method, the cyclorotary position of the eyes is determined by convergence, and the relationship shown in Fig. 1 is to be expected. As can be seen in Fig. 4 (upper trace), the variability of the matchings increases considerably more steeply for the nonius method. If appropriate measures were taken to counteract the cyclorotary movements, one would expect that the nonius technique should yield results similar to that of the rod horopter technique.

The results presented in this paper, as well as observations published previously, seem to indicate that the increase in stereoscopic threshold associated with increasing angle of convergence could be caused by eye-movement characteristics. It has been shown how the relationship between cyclorotary movements induced by vertical contours in the binocular field leaves a residual disparity. As a consequence, test fields used to determine stereoscopic acuity are imaged on noncorresponding retinal meridians. The cyclodisparity introduced in this way leads to an increasing variability of the Ss' matching, and it has been demonstrated experimentally how this disparity would influence the precision of the Ss' settings.

\section{REFERENCES}

ADAMS, A. J.. \& LEVENE, J. R. Stereocopic depth associated with cyclotorsional eye movements. British Journal of Physiological Optics, 1967, 24, 217-220.

ALLEN, M. J. The dependence of cyclophoria on convergence elevation and the system of axes. American Journal of Optometry, 1954, 31, 297-307

AMES, A., JR., OGLE, K. N., \& GLIDDON, G. H. Corresponding retinal points, the horopter and size and shape of ocular images. Parts I and II. Journal of the Optical Society of America, 1932, 22, Optical

AMIGO, G. Variation of stereoscopic acuity with observation distance. Journal of the Optical Society of America, 1963, 53, 630-635.
ALPERN, M. Movements of the eyes. In $H$. Davson (Ed.), The eye. Vol. 3. Muscular mechanisms. New York: Academic Press, 1962 .

BROWN, J. P., OGLE, K. N., \& REIHER, L. $S$ tereoscopic acuity and observation distance. Investigative Ophthalmology, 1963, 4, 849-859.

CAROW, $R$. Untersuchungen über die Näherungsrollung und die Hebungs-Senkungsrollung der Augen. Graefes Archiv fur Ophthalmologie, $1939,140,86-115$.

CIBIS, P. Faulty depth perception caused by cyclotorsion. Archives of Ophthalmology, 1952, 47, 31-42.

EBENHOLTZ, S. M., \& WALCHLI, R. M. Stereoscopic thresholds as a function of head- and object-orientation. Vision Research, 1965, 5, 455-461.

ELLER BR OCK, $V$. J. Experimental investigation of cylcofusion. American Journal of Optometry, 1946, 23, 327-341.

ELLERBROCK, $v$. J. Inducement of cyclofusional movements. American Journal of Optometry, 1954, 31, 553-566.

GRAHAM, C, H. Visual space perception. In C. H. Graham (Ed.), Vision and visual perception. New York: Wiley, 1965.

HELMHOLTZ, H. von. Helmholtz's treatise on physiological cptics. Vol. III. (Trans. J. C. Southall). New York: Dover, 1962.

HER ING, E. Beiträge zur Physiologie. Heft 1-5. Leipzig: Engelmann, 1861-1864.

HERING, E. Die Lehre vom Binocularen Sehen. 1. Lief. Leipzig: Engelmann, 1868

HERING, E. Der Raumsinn und die Bewegungen des Auges. In Hermanns Handbuch der Physiologie. Bd. 3, Teil 4. Leiprig: Vogel, 1879.

HERMANS, T. G. Torsion in persons with no known eye defects. Journal of Experimental Psychology, 1943, 32, 307-324.

HOFMANN, F. B., \& BIELSCHOWSKY, A. Ueber die der Wilkür entzogenen Fusionsbewegungen. Pflügers Archiv für die gesammte Physiologie, 1900, 80, 1-40.

KERTESZ, A. E., \& JONES, R. W. Human cyclofusional response. Vision Research. $1970,10,891-896$.

KRAUSKOPF, J., CORNSWEET, T. N., \& RIGGS, L. A. Analysis of eye movements during monocular and binocular fixation. Journal of the Optical Society of America, 1959, 50, 572-578.

KREKLING, S. Transformations of the horopter. (In Norwegian). Thesis, University of Oslo, 1969.

LANDOLT, F. C. Referred to by Aubert in Handbuch der gesammten Augenheilk unde. Bd. 2, Teil 2. (Hrsgb: A. Graefe and $T$. Saemisch). Leipzig: Engelmann, 1876

NAGEL, A. Ueber das Vorkommen von wahren Rollungen des Auges um die Gesichtslinie Graefes Archiv für Ophthalmologie, 1868, 14, 228-246.

NICHOLS, J. V. V. Relationship of heterophoria to depth perception in aviation. American Journal of Ophthalmology, 1950, 33, 1497.

OGLE, $K$. N The optical space sense. In $H$. Davson (Ed.), The eye. Vol. 4. Visual optics and the optical space sense. New York: Academic Press, 1962.

OGLE, K. N., \& ELLERBROCK, V. J. Cyciofusional movements. Archives of Ophthalmology, 1946, 36, 706-735.

OGLE, K. N., \& WEIL, M. P. Stereoscopic vision and the duration of the stimulus. Archives of Ophthalmology, 1958, 59, 4-17.

RIGGS, L. A., \& NIEHL, E. W. Eye movements and vision. Journal of the Optical Society of America, 1960, 50, 913-920.

SHORTESS, G. K., \& KRAUSKOPF, J 
Role of involuntary eye movements in stereoscopic acuity. Journal of the Optical Society of America, 1961, 51 . 555-559.

TSCHERMAK, A. V, Beiträge zur Lehre vom Längshoropter. Pflügers Archiv für die gesammte Physiologie, 1900, B1, 328-348.

TSCHERMAK, A. V. Beiträge zur physiologischen Optik IV
Augenbewegungen und optischer Raumsinn. In Bethe's Handbuch der normalen und pathologischen Physiologie. Bd. 12, Teil 2. Berlin: Springer, 1931.

TSCHERMAK, A. V. Methodik des optischen Raumsinnes und der A ugenbewegungen. In Abderhaldens Handbuch d. biol. Arbeitsmethoden. Abt. V, Bd. 6, Teil 2. Berlin/Wien, 1937.
Pp. 1427-1754.

TSCHERMAK, A. V. Introduction to physiological optics. (Trans.P. Boeder The American Committee on Optics and $V$ isual Physiology) springfield, Il Thomas, 1954.

(Received for publication January 24, 1972 ; revision received July 11,1972 .) 